\title{
O EXERCÍCIO DA CIDADANIA NA SOCIEDADE BRASILEIRA: REFLEXÃO A PARTIR DAS OCUPAÇÕES DAS ESCOLAS ESTADUAIS PAULISTAS EM 2015
}

\author{
Roseli Trevisan Marques de Souza ${ }^{1}$
}

\section{RESUMO}

O escrito intenta refletir sobre o exercício da cidadania na sociedade brasileira a partir de alguns fatos observados antes e durante as ocupações das Escolas Estaduais Paulistas em 2015. Cabe destacar que foi proposta a reorganização das unidades do Estado Paulista e no discurso governamental veiculado ressaltava que essa política pública traria benefícios aos estudantes da Educação Básica. Mas, quais? Essa questão permeou o pensamento dos jovens estudantes, movendo-os a uma reação de repúdio, condizente com a ideia de exercício da cidadania e pertinente às sociedades que têm como regime a democracia.

Palavras-chave: Democracia. Reorganização. Ocupações. Estudantes. Educação Básica.

\section{INTRODUÇÃO}

A sociedade contemporânea se demonstra pautada em um condensado de ideias que auxiliaram na formação humana e das sociedades. Um dos conceitos que permeia a realidade social há alguns séculos é o de democracia, o qual tem vínculo estreito com os termos cidadão e participação coletiva, que nada mais é do que o exercício da cidadania. Ocorre que, desde a era clássica, o termo cidadania é um conceito abstrato, pois sabe-se que nem todos podiam exercer um papel social de forma igualitária. Sabe-se também que nem todos eram beneficiados nas decisões desse grupo político, ou seja, havia uma divisão social. Independentemente dessa realidade, os representantes dessas sociedades debatiam e deliberavam.

Ainda hoje a ideia de cidadania ativa e de ser um cidadão participativo é um objetivo dos integrantes de muitas sociedades. No entanto, a aplicação do conceito de democracia também permanece como um grande desafio a ser transposto, pois há, como antes houve, membros excluídos das decisões do e para o todo e na atualidade essa exclusão se ampliou, principalmente nos países periféricos. O excluído é cidadão?

Fábio Konder Comparato, no título Educação, Estado e Poder (1987, p.30) considera que o poder pode ser caracterizado como um valor social supremo exercido pelo Estado.

\footnotetext{
${ }^{1}$ Doutora em Educação pela Universidade de São Paulo (USP). E-mail: rtms1962@gmail.com
} 
Segundo ele, este é o "grande organismo de poder político" (Ibidem, p.34), opondo-se ao poder pessoal, que envolve a ideia de exercício da cidadania.

Para Konder (1987), a cidadania vai além de ser um membro de uma dada sociedade com direitos a serem garantidos e deveres a serem executados. Implica em ter-se uma nação regida por uma Constituição aprovada no legislativo, mas também na participação, ou seja, na decisão e no acompanhamento conjunto dos processos de desenvolvimento; avaliando o processo; pensando nas mudanças, caso o andamento não esteja de acordo com o que se esperava para o coletivo.

É fato que somos parte de uma nação e por isso, já somos cidadãos, mas a partir da descrição de Konder, ser parte, de fato, está condicionado a uma postura de envolvimento. Para o autor, enfim, nós nos tornamos cidadãos se estivermos inseridos no contexto e interagindo com ele. Desta forma, numa sociedade como a brasileira, marcada pelo autoritarismo inerente ao patriarcado, é preciso aprender constantemente sobre tomada de decisão coletiva. Tal aprendizagem se dará em espaços de diálogo e a escola certamente é um deles.

Outro aspecto, no que consiste a ser visto como cidadão, está na obra A Construção Social da Subcidadania: para uma sociologia política da modernidade periférica, de Jessé Souza (2012), em que afirma que a desigualdade social implica no ostracismo ${ }^{2}$ participativo. Ele diz que essa condição social se dá pela "hierarquia valorativa" existente nas sociedades de extrema desigualdade social originada do sistema econômico reinante, definindo "quem é ou não é "gente" (...) e por consequência quem é ou não cidadão." (2012, p. 181). Diz também que estamos em uma sociedade democrática aberta (2012, p. 180), ancorada na lógica da dominação simbólica que também separa/divide e exclui, quando desvaloriza as culturas populares, deflagrando a ideia de "subcultura" e consequentemente de "subpolítica". Ou seja, há uma divisão social que prioriza os valores e a participação de apenas uma parcela da sociedade.

Um dos aspectos que possibilitam essa divisão social é a educação escolar como direito, mas, é claro, uma educação para a participação. A educação formal é um direito à população e um dever do Estado. Essa fala está posta na Constituição Federal de 1988 e reafirmada na Lei de Diretrizes e Bases da Educação, n 9394/96. Trata de uma educação pública e gratuita, garantindo também o acesso dos estudantes às unidades escolares de todas as classes sociais, da permanência deles, bem como da qualidade da aprendizagem desses alunos. Pelo menos na lei, são alvos a serem atingidos. Mas, na verdade, quando se verifica a prática quanto aos amplos direitos educacionais, deparamo-nos com as políticas públicas educacionais que são aplicadas

\footnotetext{
${ }^{2}$ Termo utilizado nesse artigo no sentido de participação política. Segundo o dicionário Houaiss, na antiga Grécia, o termo significava desterro político e atualmente envolve também exclusão política.
} 
sem o conhecimento da população. Em quais aspectos as lideranças governamentais contribuem para que haja um cenário social participativo?

Segundo Paes-Sousa; Hellmann $(2013)^{3}$, as políticas públicas no Brasil não costumam ser elaboradas com a contribuição direta dos que por elas são afetados. Um movimento no sentido da participação coletiva requereria a descentralização das decisões, implicando na inserção dos mais pobres nos debates políticos. Se compreendermos desta forma, a decisão de reorganizar as escolas foi uma decisão arbitrária dos governantes de São Paulo e os jovens, ao refutá-la, exerceram seu direito posto em Constituição, de serem contrários à determinação legal e de se afirmarem nesse processo como cidadãos participativos.

\section{A REORGANIZAÇÃO DAS ESCOLAS}

Destaca-se que o procedimento da reorganização englobava duas ações iniciais: fechar 94 prédios escolares e remanejar um grande número de discentes e docentes. Tais decisões levaram os jovens à ocupação paulatina de 200 escolas no Estado de São Paulo. O Governo estadual promulgou o Decreto $\mathrm{n}^{\circ}$ 61.672, de 30-11-2015 e, por resistência dos jovens, em 0412-2015, foi publicado o Decreto $\mathrm{n}^{\mathrm{o}}$ 61.692, revogando o anterior. Isto é, não houve reorganização devido à ação cidadã dos discentes.

Antes mesmo da publicação no Diário Oficial do Estado da decisão governamental de reorganizar, os discentes se organizaram para compreender o que estava acontecendo e, após a interpretação dos fatos e aos debates sobre como reagir ao pleito, iniciaram as ocupações. No que se refere à ideia de reorganização, esse termo compõe o léxico das políticas públicas há algumas décadas. Inclusive em 1995, em São Paulo, houve uma similar, que vingou, não sofrendo a resistência que houve em 2015.

Ressalta-se que desde 1995 muitas escolas da Educação Básica, por todos os estados do Brasil, têm sido fechadas. Segundo Eliza Botolozzi Ferreira (2009, p.255) ${ }^{4}$, "as reformas empreendidas na década de 1990 tentaram redimensionar o Estado, revesti-lo de novas competências e funções, não mais promotor direto do crescimento econômico, mas somente catalizador e facilitador".

\footnotetext{
${ }^{3}$ PAES-SOUSA, R.; HELLMANN, A. Monitoring and evaluation systems: recent advances in Brazil's federal public administration. In: VAITSMAN, J.; RIBEIRO, J.M.; LOBATO, L. (Orgs.). Policy Analysis in Brazil. Bristol: Polity Press, 2013.

${ }^{4}$ FERREIRA, Eliza B. A contrarreforma do Ensino Médio no contexto da nova ordem e progresso. A produção deste texto está inserida nos estudos desenvolvidos na pesquisa "Programa ensino médio inovador: condições de trabalho e formação docente". Disponível em: http://www.scielo.br/pdf/es/v38n139/1678-4626-es38-139-00293.pdf acesso em: 24 mar.2019.
} 
Mas, independentemente desse cenário, uma nova forma de resistência dos alunos da educação básica foi iniciada a partir de 2012, em Goiás: uma escola seria fechada e os estudantes a ocuparam, revertendo o pleito. Em 2015, o mesmo movimento aconteceu, foi maior e ganhou espaço nas redes sociais, na mídia formal e informal. Os estudantes da educação básica, nesse segundo ato, contaram com o apoio de parcela da sociedade para reverter o autoritarismo governamental.

Foi um período curto de manifestações, mas crucial, pois o ano letivo estava por finalizar. Ressalta-se ainda que esse momento poderia ter passado despercebido se pesquisadores, em geral do campo da educação, não registrassem o histórico (SOUZA; CATANI, 2019). Os estudos têm trazido luz aos discentes como atores políticos e à realidade educacional que os envolvia. Compreendeu-se que a sociedade brasileira estava diante de cidadãos que cumpriam seu papel social, independente do poder exercido pelo estado sobre o todo. Trata-se de um fenômeno social, vinculado a um novo despertar do estudante brasileiro para a vivência da democracia, descontruindo a ideia de que o poder deve permanecer nas mãos de alguns privilegiados, esses sim poderão ter voz no todo. Jessé Souza (2012, p. 64) diz que:

Nas sociedades periféricas modernizadas de fora para dentro, como a brasileira, "gente" vai ser o "europeu". Embora em São Paulo, cidade analisada por Florestan Fernandes em seu estudo, o referente empírico da "europeidade" seja efetivamente em "europeu", no caso o imigrante italiano.

Diante desse discurso, observa-se que o preconceito grita alto em São Paulo e quem não é parte plena dessa elite jamais ganhará status de cidadão. No máximo, terá que batalhar muito para sobreviver, pois escola de qualidade nesse contexto é apenas um luxo.

\section{O PODER HEGEMÔNICO}

De Maquiavel, passando por Hobbes até a contemporaneidade, muitos pensadores têm relatado, sob várias perspectivas, o papel que este organismo estatal desempenha na sociedade. Em Sobre o Estado: cursos no Collège de France 1989-92 (2014, p.30), Pierre Bourdieu referese ao Estado como "campo de poder". Diz também que o Estado Moderno tem o poder simbólico como dimensão que o legitima.

Nos últimos 30 anos, comumente, esse exercício da cidadania por parte dos estudantes da educação básica ficou relegado, principalmente pelos membros dessa faixa etária na sociedade brasileira, pois a maioria dos jovens transferia esse papel para aqueles que estão nos congressos/assembleias. Van Dijk, em Discurso e Poder (2004), destaca que a linguagem da 
elite simbólica contribui para uma redução participativa, e que o discurso dos integrantes das arenas políticas precisa ser alvo de estudos, caso se objetive participação ampla nas decisões de dada sociedade. No segundo capítulo do livro desse autor, ele analisa como é exercido o poder social, apresenta as principais características dessa ação e, finalmente demonstra como a classe hegemônica produz e veicula falas, cuja intenção é o controle cognitivo e ideológico da população de dominados.

Segundo Gramsci (1962), a sociedade civil se constitui em organismo de resistência ao estado, mas no Brasil, a sociedade civil com representatividade é aquela que também participa das fatias do bolo da classe dominante. A partir de 1990, sindicatos e representantes de movimentos sociais, por exemplo, costumam ser excluídos das decisões que envolvem o todo, comprometendo a participação de alguns membros da sociedade civil e ampliando a ideia de domínio de uma classe sobre outra.

Os participantes das ocupações, naquele momento, reconheceram a necessidade da existência de uma nova concepção de estado, de educação, de política e de cidadania similar ao descrito na Constituição Federal de 1988. Para eles, o autoritarismo do governo era um aspecto que distorcia o papel estatal posto na Carta Magna e era necessário esse resgate por meio de um movimento estudantil. Boaventura de Souza Santos (2002, p. 26) diz que os ativistas e líderes de movimentos e organizações populares aprendem na luta contra os poderes hegemônicos o saber prático que faz mover o mundo, e mais do que qualquer outro, dá sentido ao mundo.

\section{ESTADO X SOCIEDADE}

Os movimentos estudantis não são novidades no mundo e no Brasil. Sabe-se, também, que as tensões entre estado e sociedade são recorrentemente a mola mestra dos movimentos sociais. Destacamos os movimentos da década de 1960. Entre 1964 e 1965 tem-se as manifestações no campus da Universidade da Califórnia em Berkeley. Nesse período, outros movimentos ocorreram ainda nos Estados Unidos da América, bem como na Europa e no Brasil a partir de 1968.

Na década de 1990, outras manifestações jovens. Ressaltamos os eventos em Seattle em 1999. No século XXI, em 2011, no Ocuppy Wall Street, jovens indignados pela falta de ética, de moral, de valores e de justiça social se manifestaram (GOHN, 1997) ${ }^{5}$. Em 2013, o 
Movimento do Passe Livre. No mesmo ano, na USP, houve também ocupação da reitoria para definir linha de trabalho no Campus.

Boaventura de Souza Santos, no livro Democratizar a Democracia: os caminhos da democracia participativa (2002), afirma que há olhares cuidadosos dos pesquisadores para a globalização, para a democratização e para o neoliberalismo. Estudam-se as formas que os ativistas e outros manifestantes refutam as práticas regulatórias dadas por políticas públicas. $\mathrm{Na}$ obra organizada por ele, há a preocupação em atribuir sentido à expressão "democracia participativa", tendo em vista que guarda estreita relação com o tipo de governo e de sociedade vigente em um país.

Geralmente, os movimentos decorrem de uma realidade mundial, na qual o Estado vem redefinindo seu papel, se propondo a minimizar os deveres a serem cumpridos com o todo social, com base nos pressupostos neoliberais. No Brasil, a partir de 1995, reformas educacionais foram empreendidas e escolas da educação básica foram fechadas. As práticas de descentralização administrativa foram aplicadas com a finalidade de privatização da gestão pública. Ferreira (Ibidem, p. 256) diz: “a reforma buscou consolidar a figura de um estado gerencial, com capacidade de regulação social mediante a transferência a outros setores/instituições da responsabilidade de prestação dos serviços sociais".

À administração gerencialista, agrega-se um Estado que usa instrumentos de violência para garantir o poder político e econômico nas mãos de poucos. O Estado existe, enfim, como instituição a serviço da classe hegemônica, inibindo a resistência de outros segmentos da sociedade com políticas públicas autoritárias e excludentes e com ações de contenção social.

Continuando a análise sobre o gerenciamento do Estado com base nos princípios neoliberais, no artigo intitulado Limitações da Participação e Gestão Democrática na Rede Estadual paulista, publicado na "Revista de Ciências da Educação", vol. 37, out-dez de 2016 (CEDES, $n^{\circ}$ 137. p. 1153), nota-se que essa medida governamental, na verdade, tinha como referência o mesmo gerenciamento aplicado em 1995. Segundo Dalila Oliveira (2009, p.25), no capítulo Política educativa, crise da escola e a promoção da justiça social, do livro "Crise da Escola e Políticas Educativas", a inabilidade estatal em atuar em face dos pressupostos que regulamentam a educação fundamental no Brasil é um fato recorrente em países pobres e populosos em todo o mundo. Trata-se de uma crise ainda carente de administração no século XXI, e isso ocorre, principalmente, devido à política neoliberal que tem postulado antagônica ao descrito no artigo 205 da Carta Magna e da LDB 9.394/96. 
Teóricos como Dalila (2009), Frigotto (2009) e Mészáros (2008) afirmam que o posicionamento estatal a favor dos pressupostos neoliberais fere o direito à educação, a formação para a cidadania e à qualidade de ensino. Em 2017, o Secretário da Educação de São Paulo, da época, escreveu um livro intitulado: A Educação Básica pública tem solução? (VOORWARD, 2017). Nele, o autor justificou que a reorganização tem como motivação "a diminuição no número de matrículas na Rede Pública da Educação Básica do Estado de São Paulo e a mobilidade populacional nos últimos anos" (VOORWARD, 2017, p. 108). Ademais, diz ter considerado mais algumas premissas: "modelos de escola; tamanho de escola; estrutura física; e logística" (Ibidem, p. 108). Ou seja, na ação, compreenderam a necessidade de realocar alunos, funcionários e professores das escolas que seriam fechadas em outros prédios, reduzindo assim o número de unidades escolares sob a responsabilidade do Estado.

Quando utilizada a expressão "modelos de escola" (grifo nosso) pensava-se na ampliação do ensino médio diurno com ensino integral, que é uma das metas do Plano Nacional de Educação (MEC, 2014-2024), mas e o que aconteceria com os estudantes do ensino médio noturno? O que se fariam com a evasão crescente dos estudantes desse segmento? As respostas para essas questões, na atualidade, são claras. A ideia era simplesmente reorganizar, adequando utilização dos recursos públicos (SOUZA; CATANI, 2019). Na leitura do livro de Voorward, não se observa a busca por compreensão dos reais motivos para a redução das matrículas, bem como uma reflexão sobre os desdobramentos dessa política, em especial, o aumento da evasão escolar.

Independentemente dessa realidade de exclusão política, uma parcela de jovens de alguns países da América Latina tem atuado contra os desmandos governamentais. No que se refere à educação, temos como exemplo, as ocupações das escolas no Chile em 2006, depois na Argentina em 2011; em seguida, no Brasil, em 2012, 2013, 2015 e em 2016, quando ocorreram ocupações nas escolas do Sul, do Centro-Oeste e do Nordeste Brasileiro, colocando em xeque a pretensa racionalidade política e a doutrina do Estado neoliberal. A prática desenvolvida tem sido destacada ao longo do texto, uma prática cidadã. Mas, quem são esses jovens e de onde nasceu essa disposição à participação tem sido nosso questionamento atual para futura publicação.

\section{A VEICULAÇÃO E O PLANEJAMENTO DA REORGANIZAÇÃO}

Retomando ao tema deste capítulo, o que denota o autoritarismo dessa política pública? Alguns aspectos já foram ditos, um deles é a necessidade da redução de gastos da máquina 
pública em detrimento da qualidade na aprendizagem. Gostaríamos de destacar, ainda, um caminho trilhado pela SEE/SP e os objetivos específicos para impor a política governamental.

Em São Paulo, foi veiculado um paper pela Secretaria da Educação de São Paulo (SEE/SP), apontando o decréscimo demográfico como motivo para o fechamento de escolas. Santos e Vieira (2017) dizem:

\begin{abstract}
Assumindo que o índice de envelhecimento teria pouca variação entre 2010 e 2016, observamos que 15, das 25 escolas da capital a serem fechadas, estão em áreas onde atualmente consta um baixo índice de envelhecimento populacional. No entanto, onze escolas estão em áreas em que nos próximos quinze anos há tendência de envelhecimento - isto é, a diminuição do número de crianças e o aumento do número de pessoas com mais de 60 anos. Apenas cinco escolas, situadas em regiões periféricas (quatro no extremo leste - Guaianases, Lajeado e São Miguel; e uma na zona sul - Capão Redondo) estão em áreas em que deverá persistir uma baixa razão de idosos (2017, p.13).
\end{abstract}

Ademais, no artigo intitulado A geografia da reorganização escolar: uma análise espacial a partir da cidade de São Paulo, há um mapa da reorganização das escolas elaborado por Eduardo Donizete Girotto, Felipe Garcia Passos, Larissa Campos e João Oliveira (2017), e nele se encontram outros motivos para reorganizar as escolas, como por exemplo, atendimento ao mercado imobiliário e a construção de linhas do Metrô na cidade de São Paulo.

Segundo se observa no texto de Emir Sader (2008, p.15), que prefacia o livro de Mészáros (2008), A educação para além do capital, a decisão de fechar escolas tem origem mercadológica e coloca a educação básica pública "como instrumento de poder capitalista" (2008, p.16). Ele completa: "No reino do capital, a educação é, ela mesma, uma mercadoria. Daí a crise do sistema público de ensino, pressionado pelas demandas do capital e pelo esmagamento dos cortes de recursos dos orçamentos públicos". Ou seja, a veiculação foi mínima e o planejamento estava pautado em captação de recursos para o Estado, disponibilizando terrenos das escolas centralizadas para a inciativa privada, aglomerando os alunos das unidades nas regiões periféricas, deflagrando a existência de espaços de exclusão e validando a condição de uma sociedade desigual.

\title{
A DESIGUALDADE SOCIAL
}

A desigualdade social é o resultado da grande exploração do trabalho, ação própria do sistema capitalista. Nessa concepção de mundo, como destaca Jessé Souza (2012, p. 181), fica evidente quem é ou não participe da dimensão sociopolítica, apenas uma elite. A grande parcela da sociedade está excluída das decisões, por isso, nesse modelo de sociedade não há, de fato, preocupação com formação para o exercício da cidadania. 
Para Boaventura de Souza Santos (2002, p.22), no plano organizacional, se a sociedade vive uma realidade contrária ao conceito de democracia, a proletarização social se instaura e poderá ser alterada quando a população excluída resistir à condição desigual e atuar contra hegemonicamente, inibindo a lógica do capitalismo global, ou seja, quando os membros dominados buscarem conjuntamente a emancipação social. Segundo o mesmo autor, a resistência comumente é protagonizada por ativistas e líderes de movimentos e organizações populares que confrontam as forças de poder, dando sentido às relações humanas no mundo. Essas articulações são aprendidas no cotidiano de uma formação cidadã e representam uma das formas de conquista da democracia participativa.

$\mathrm{Na}$ proposta de reorganização escolar em 2015, por exemplo, seria remanejado um número significativo de discentes e docentes. Os jovens não suportaram essa ideia e resistiram à decisão. Eles estavam sendo impulsionados a um novo convívio escolar, deixando para trás, subitamente, as amizades travadas ao longo da escolaridade, o espaço escolar e os professores que conheciam. O aluno seria alocado em uma escola vizinha. Mas as possibilidades de mudança, fossem quais fossem, os expunha à violência simbólica e deixava evidente a condição de dominados no cenário social. Os estudantes submetidos à realidade descrita apresentavam sinais de insatisfação, indignação diante da forma de como se deu o processo de reorganização, por isso ocuparam as escolas públicas do estado de São Paulo. Nota-se, nesse cenário, que a voz deles não importava à Secretaria Estadual de Educação/SP.

Conforme evidenciado, nota-se que a educação brasileira convive com leis pautadas no ideário democrático, porém, na prática, vivenciam políticas governamentais próprias do neoliberalismo que deixam evidentes a divisão social e a pouca responsabilidade do Estado com quem está no lado frágil dessa sociedade. Diante disso, infere-se que a ação governamental tinha como foco privilegiar os já privilegiados, foi simbolicamente violenta, pouco preocupada com a construção de uma sociedade verdadeiramente democrático-participativa. Com efeito, a população precisa estar em constante alerta para fazer valer seus direitos e foi justamente isso que fizeram os jovens que ocuparam as escolas de São Paulo em 2015.

Para Boaventura de Souza Santos (2002, p. 27), "a democracia participativa confronta privilegiadamente a dominação, o patriarcado e a diferenciação identitária desigual". Diz também que a ação de resistência confronta todas as formas de poder, resulta na emancipação social e conseguintemente no aprendizado da cidadania e no ato de se tornar cidadão. Apesar dessa realidade, observa-se que ainda existe uma grande barreira a ser derrubada para que os mais pobres possam, de fato, participar das decisões. São avanços e retrocessos que fazem da jornada democrática ser exaustiva e contar com poucos ajudadores. Estratégias dos governos 
autoritários contra a educação são recorrentemente utilizadas no intuito de que a sociedade não conte com a participação efetiva do todo.

\section{CONSIDERAÇÕES FINAIS}

Registrou-se nesse texto, portanto, pouca ou nenhuma sensibilidade do poder público com as necessidades reais de educação da população, resultado dessa insensibilidade se expressa pela realidade da evasão escolar/abandono e pelas escolas cada dia mais deterioradas e com um quadro insuficiente de professores e funcionários. Destaca-se nesse sentido, a ocorrência da lógica internalizada da política econômica neoliberal que está desconstruindo o conceito de educação escolarizada e que aposta no aumento da desigualdade social para se manter firme. Desta forma, a omissão do Estado em investir na melhoria da escola pública de educação básica, resulta no aumento da exclusão social.

Existe uma legislação que visa a garantir a educação formal. A Constituição Federal de 1988 é um repositório do direito alegadamente plurilateral, mas, na prática, nem todos são iguais perante a lei. Alguns têm mais privilégios que outros. Atuar contra hegemonicamente é a forma de garantir os direitos de todos. Nesse sentido, são os movimentos estudantis que tem feito esse papel, bem como o sindicato dos professores e os membros da academia diretamente vinculados à educação.

O que se tem, então, é um pacto entre o Estado e o Capital Financeiro com vistas ao controle da população e ao atendimento dos interesses de quem detém o capital, e nesse processo desqualificam e reprimem toda resistência social, fragilizando as ações desses grupos preocupados com esta realidade opressiva. $\mathrm{O}$ alvo mais atingido é a educação para o povo, pois sem essa educação a participação coletiva jamais se ampliará, ou seja, não teremos descentralização do poder.

No que concerne à Educação Básica pública do Estado de São Paulo, os líderes governamentais tem seguido uma linha condutora, culminando no esvaziamento escolar, no aumento da desigualdade social e na ampliação da exclusão social. Contra esse estado de coisas, em São Paulo, em 2015, alguns estudantes se manifestaram, mas, em 2020, não se observa uma atuação efetiva para inibir o avanço desse autoritarismo. Caberia compreender esse silêncio. Trata-se de um recuo aos ideais de cidadania e de democracia dos jovens ou de uma opressão/repressão velada por parte dos órgãos governamentais? Essa dúvida não será esclarecida, mas temos como fato, mediante ao observado nas ocupações e depois em outros eventos similares de jovens estudantes por todo o Brasil, que a formação cidadã está fragilizada 
em nosso país por interferência de um Estado que quer apenas dominar e não emancipar seu povo.

\section{REFERÊNCIAS}

BOURDIEU, P. Sobre o Estado: Cursos no Collège de France (1989-92). São Paulo: Companhia das Letras, 2012.

BRASIL. Constituição da República Federativa do Brasil: promulgada em 5 de outubro de 1988. Brasília, $1988 . \quad$ Disponível em: http://www.planalto.gov.br/ccivil_03/constituicao/constituicao.htm. Acesso em: 29 mar. 2020.

Lei $\mathbf{n}^{\circ}$ 13.415, de 2017. Altera as Leis $n^{\circ}$ 9.394, de 20 de dezembro de 1996, que estabelece as diretrizes e bases da educação nacional, e 11.494, de 20 de junho 2007, que regulamenta o Fundo de Manutenção e Desenvolvimento da Educação Básica e de Valorização dos Profissionais da Educação, a Consolidação das Leis do Trabalho - CLT, aprovada pelo Decreto-Lei $n^{\circ} 5.452$, de $1^{\circ}$ de maio de 1943, e o Decreto-Lei $n^{\circ} 236$, de 28 de fevereiro de 1967; revoga a Lei $\mathrm{n}^{\circ} 11.161$, de 5 de agosto de 2005; e institui a Política de Fomento à Implementação de Escolas de Ensino Médio em Tempo Integral. Disponível em: http://www.planalto.gov.br/ccivil_03/_Ato2015-2018/2017/Lei/L13415.htm. Acesso em: 25 de mar. 2020.

CASTELO BRANCO, G.; BAÊTA, L. F. N. (Orgs.) Michel Foucault: da arqueologia do saber à estética da existência. Rio de Janeiro: Nau, 1999.

FERREIRA E. B.; POCHMAN M. Escolarização de jovens e igualdade no exercício do direito à educação no Brasil: embates do início do Século XXI. Educação e Sociedade, Campinas, v. 37, n. 137, p. 1241-1270, jan./maio 2016.

FOUCAULT, M. Estratégia, poder-saber: ditos e escritos IV. Rio de Janeiro: Forense Universitária, 2006.

FOUCAULT, M. Aula de $1^{\circ}$ e de 8 de fevereiro de 1978. In: Segurança, Território, População: Curso dado no Collège de France (1977-1978). São Paulo: Martins Fontes, 2008a. p. 117-180. 293. Governamentalidade. In: Microfísica do Poder. Rio de Janeiro: Graal, 1979. p. 277 -

GIROTTO, E. D. A dimensão espacial da escola pública: leituras sobre a reorganização da rede estadual de São Paulo. Educação e Sociedade, Campinas, v. 37, n. 137, p. 1121-1141, out./dez. 2016.

GIROTTO, E. D et al. A geografia da reorganização escolar: uma análise espacial a partir da cidade de São Paulo. ETD - Educação Temática Digital, Campinas, v. 19, n. especial, p. 134-
158 ,
jan./mar.
2017.
Disponível
em: 
https://periodicos.sbu.unicamp.br/ojs/index.php/etd/article/view/8647805/15187. Acesso em: 25 nov. 2017.

GOHN, M. da G. Movimentos Sociais e educação. São Paulo: Cortez, 2013.

GOULART, D. C.; PINTO, J. M. R.; CAMARGO, R. B. de. Duas reorganizações (1995-2015): do esvaziamento da rede pública estadual paulista à ocupação das escolas. ETD - Educação Temática Digital, Campinas, v. 19, n. 1, p. 109-133, jan./mar. 2017. Disponível em: https://periodicos.sbu.unicamp.br/ojs/index.php/etd/article/view/8647797/15186. Acesso em: 20 mar. 2020.

GRABOIS, P. F. Resistência e revolução no pensamento de Michel Foucault: contracondutas, sublevações e lutas. Cadernos de Ética e Filosofia Política, v. 19, São Paulo. 2011. Disponível em: http://www.revistas.usp.br/cefp/article/view/55736.

GRAMSCI, A. Notas sobre Maquiavel, sobre política y sobre el Estado moderno. Buenos Aires: Lautaro, 1962.

LE GOFF, J. et.al. História e Memória. Campinas: Editora Unicamp, 1996.

LONGO, F. Demografia e Educação II: a reorganização escolar em São Paulo. São Paulo, 2017. Disponível em: https://demografiaunicamp.wordpress.com/2017/05/02/demografia-eeducacao-ii-a-reorganizacao-escolar-em-sao-paulo/. Acesso em: 14 jan. 2020.

MÉSZÁROS, I. A educação para além do capital. São Paulo: Boitempo, 2008.

NALINI, J. R. A reorganização escolar foi feita em gabinete, sem se abrir à discussão. Jornal El País, Brasil, 18 out. 2016. Disponível em: https://brasil.elpais.com/brasil/2016/09/22/politica/1474568354_586576.html. Acesso em: 18 nov. 2017.

NUNCA ME SONHARAM: documentário. Direção de Cacau Rhoden. 2017. Disponível em: https://www.youtube.com/watch?v=KB-GVV68U5s. Acesso em: 27 mar. 2020.

O MAL-EDUCADO. São Paulo, 2016. Disponível em: http://gremiolivre.wordpress.com. Acesso em: 14 jan. 2020.

PAPARELLI, R. Desgaste mental do professor da rede pública de ensino: trabalho sem sentido sob a política de regularização de fluxo escolar. 2009. 184 f. Tese (Doutorado) Instituto de Psicologia, Universidade de São Paulo, São Paulo, 2009.

SANTOS, B. S. Democratizar a democracia: os caminhos da democracia participativa. Porto: Afrontamento, 2003.

SANTOS, F. V. L. dos; VIEIRA, J. M. A reorganização escolar em São Paulo: uma reflexão sobre o uso de argumentos demográficos em políticas educacionais. [S.l.: s.n.]. Disponível em: http://abep.org.br/xxencontro/files/paper/175-321.pdf. Acesso em: 29 mar. 2020.

SÃO PAUlO. A Nova Estrutura Administrativa da Secretaria da Educação do Estado de São Paulo: Por uma Gestão de Resultado com Foco no Desempenho do Aluno. São Paulo: Secretaria da Educação, $2013 . \quad$ Disponível em: 
http://www.educacao.sp.gov.br/a2sitebox/arquivos/documentos/572.pdf. Acesso em: 20 jan. 2020.

Decreto n. ${ }^{\circ}$ 57.141, de 18 de julho de 2011: reorganiza a Secretaria da Educação e dá providências correlatas. São Paulo, 2011. Disponível em: https://www.al.sp.gov.br/repositorio/legislacao/decreto/2011/decreto-57141-18.07.2011.html. Acesso em: 20 jan. 2020.

Decreto n. ${ }^{\circ}$ 61.692, de 4 de dezembro de 2015. Revoga o Decreto n. ${ }^{\circ} 61.672$, de 30 de novembro de 2015. São Paulo, 2015a. Disponível em: http://www.al.sp.gov.br/repositorio/legislacao/decreto/2015/decreto-61692-04.12.2015.html. Acesso em: 18 nov. 2020.

SOUZA, R. T. M. de, \& CATANI, A. M. (2019). Movimento Estudantil: as ocupações nas escolas estaduais de São Paulo. Revista Inter Ação, 44(2), 475-498.

SOUZA, R. T. M. de. Escola pública do estado de São Paulo: inclusão ou exclusão social? In: MARIANO, Hélvio Alexandre. Infância e Seus Lugares. São Paulo: Paco Editorial, 2018.

TEDESCO, J. C. Qualidade na educação e políticas educacionais. Brasília, DF: Liber Livros, 2012.

VAN DIJK, T. A. Discurso e Poder. São Paulo: Contexto, 2008.

VOORWARD H. J. C. A educação Pública tem solução? São Paulo: editora Unesp, 2017. 